\title{
The Effect of Structural Factors on Managerial Autonomy of Public Organizations: A Study of Agencification in Pakistan
}

\author{
Muhammad Zeb Khan ${ }^{1}$, Muhammad Siddique ${ }^{2}$, Zia Ullah ${ }^{3}$
}

\begin{abstract}
Driven mainly by NPM (New Public Management) ideology, there has been increased agencification in Pakistan since the mid-1980s. The avowed objective of creating autonomous agencies is to free public managers from the direct control of political executives in financial and human resource management as a recipe for bureau-pathologies. This study examines the effect of structural characteristics of public organizations on their autonomy in the province of Khyber Pukhtunkhwa (Pakistan). The study is interesting in that it focuses on agencies within a common political-administrative context which makes the causal analysis of different agencies more meaningful. Based on the ideas from structural-instrumental perspective, this study tests a model of public agencies governance, developed by Koen Verhoest, by drawing on data collected from key respondents through standardized survey. Both descriptive and inferential statistical techniques have been used to make sense of the data and test various hypotheses. The results show that some structural factors do matter in determining the autonomy of public agencies.
\end{abstract}

Key Words: Public sector reforms, structural-instrumental perspective, organizational autonomy, performance

\section{Introduction}

The role of government has always been a contested terrain. Keynes (1936) contend that government can and should intervene in economy for political as well as economic reasons such as raising or reducing prices, promoting economic growth, increasing employment or addressing market failure. Market failure is often linked

\footnotetext{
1 Associate Professor, Department of Management Sciences, SZABIST, Islamabad.

Email:dr.zeb@szabist-isb.edu.pk

2 Assistant Professor, Institute of Management Sciences, Peshawar

Email: muhammad.siddique@imsciences.edu.pk

3 Professor, Lahore Leads university, Lahore. Email: qziaullah@gmail.com
}

\section{ARTICLE HISTORY \\ 11 Dec, 2018 Submission Received \\ 03 Apr, 2019 Second Review \\ 08 Feb, 2019 First Review

28 July, 2019 Third Review

08 Aug, 2019 Accepted 
with information asymmetries, externalities, natural monopoly, principal-agent problem, and public goods (Stiglitz, 1998). Others believe that welfare states have become overburdened, unaffordable, ineffective, and constraining (O'Connor, 1973; Held, 1984) that needed to cut to size through reforms. The underlying desire of proponents of both views has been to make governments more efficient and responsiveness to the citizens (Pollitt, 1993). The drive for more efficiency and improved quality of service kept spreading around the world during the 1980s and 1990s under the rubric of New Public Management (NPM) with a promise to cure every bureaupathology including rigidity, trained incapacity, inefficiency, and rent seeking. The scope and pace of NPM-type reforms have, however, not only become contested but also have been context-specific in contrast to theoretical speculations about its universal relevance/ application (Jonker, 2012).

The reforms of 1980s and 1990s lent support to fragmented public sector, producing single-or few-purpose entities, each pursuing specifically defined goals (James $\&$ VanThiel, 2011). The single-purpose agencies were deliberately positioned at arm's length from core bureaucracy, partly to give managers greater authority and freedom to manage (Pollitt, Talbot, Caulfield, \& Smullen, 2004). But due to the existence of more and more autonomous/semi-autonomous organizations, the concern for coordination and accountability of governments were raised in several studies (Verhoest, Roness, Verschuere, Rubecksen, \& MacCarthaigh, 2010; Bertelli, Sinclair, \& Lee, 2015). This led to post-NPM reform agenda under new concepts such as 'joined-up government' and 'network governance' (Christensen, Lægreid, Roness, \& Røvik, 2007; Overman, VanThiel \& Lafarge, 2014). The post-NPM type reforms gained currency in the wake of dealing with more complex problems such as fighting natural disasters and terrorism in addition to restoring trust in the public sector (Chamon, 2016; Scott, 2016).

Like many other countries, Pakistan has been making efforts since its independence in 1947, to revamp its institutions to make them vibrant and effective for meeting the growing public demands of socio-economic development and security. Some of the initiatives have yielded positive results and some have not moved beyond political rhetoric (Shafqat, 1997). Pakistani bureaucracy is still characterized by inefficiency, rigidity, lack of responsiveness, and elitism (Kennedy, 1988). The government of Khyber Pukhtunkhwa (KP), which is a province of Pakistan, has initiated several administrative reforms in response to systemic problems in public organizations. The government has had to cut back, to reduce expenditures, and to demand better performance from its sluggish public sectors in order to position itself in the emerging world economy. One visible trend in KP to reform public administration has been a greater emphasis on the use of agencies with regulatory and/or service delivery func- 
tions since 1980s. During the last few decades, though the number of agencies has increased but they still work within public administration that has strong bureaucratic traditions and weak political institutions (Rizwan \& Jadoon, 2010). Practically, the creation of autonomous agencies, led by professional managers and evaluated on the basis of results achieved, is an idea still not so popular within the colonial bureaucratic system of Pakistan (Hussain, 2005). The study in question seeks to investigate the context, nature, and role of autonomous/semi-autonomous agencies operating under Khyber-Pukhtunkhwa (KP) government. More importantly it examines structural factors that lead to enhancing organizational autonomy.

The phenomenon of agencification has been the focus of research for the last few years (Verschuere, 2007). The prominent issues include the reasons for proliferation of agencies in different countries, whether or not agencies have improved efficiency and quality of public services, and the way agencies are managed (Sullen, 2010; Dan, 2014). More importantly, researchers have been examining the recurring question of how governments strike a balance between agency autonomy and the required control by parent ministries (Christensen \& Laegreid, 2006).

By creating agencies, it is assumed that granting more autonomy to public agencies will automatically induce modernization of their management practices which will ultimately translate into better performance. However, the literature also suggests that many governments embark upon reforms (creation of public agencies being one such initiative) in order to gain legitimacy from the environment (Meyer \& Rowan, 1977) and sometimes the adoption of reforms is driven by latest management fads. The environment in the case of KP reforms comprises the citizens that public organizations are supposed to serve. The agencification phenomenon, therefore, poses major challenges of conceptual, methodological, and empirical nature while conducting research in this area.

In the context of Pakistan, the phenomenon of agencification has not fully engaged researchers to examine the extent to which public sector reforms undertaken for the last sixty years under various governments reflect international pressure and/ or domestic problems. While the practical nature of administration in Pakistan has undergone many changes, the research has not been parallel to such transformations. In this regard, the study compares public sector agencies working under the government of Khyber Pukhtunkhwa in terms of their structural features, relative autonomy, and scope of operations. The study focuses on how structural differences (agency size and existence of governing board etc.) affect public sector agencies' autonomy which 
is assumed to be associated with performance orientation of an organization.

\section{Review of Literature}

The question of how to design the government structure in order to make it more efficient and effective is difficult to answer. The spread of democracy and the global integration of economies have left little scope for arbitrary behavior in imposing taxes, framing economic policies, and imposing regulations (World Bank, 1997). Traditional public administration is believed to be unfit for the job of anticipating and meeting public demands in a rapidly changing environment and has been generally diagnosed for 'bureaupathologies' including inflexibility, waste, red tapism, and impenetrability of hierarchy (Verschuere, 2007). The weaknesses of bureaucracy and crisis in the welfare state, inter alia, have led to redefining the role of state and searching for alternative ways of managing the public services by bringing in market practices and competition (Leagreid \& Verhoest, 2010). So far, New Public Management (NPM) has been presented as a more holistic model of public sector reforms (Pollitt et al., 2004; Alonso, Clifton, \& Díaz-Fuentes, 2015) even though some qualities of traditional bureaucracy, such as predictability, stability, and due process, are considered important. The principal tool of NPM paradigm is public sector agency (autonomous/semi-autonomous) which is used to address the bureau- pathologies. A public agency, according to Pollitt et al. (2004), is an organization created at arm's length from the core bureaucracy with relatively more autonomy to perform public tasks (such as regulation, service delivery) and staffed by public servants.

To be sure, agencies are mentioned as a 'good thing' in various popular prescriptive public management reform texts (Pollitt et al., 2004). There is some evidence that public administration in general has periodically cycled between an emphasis on fragmentation, coordination, and integration (through creating 'super-Ministries' for example) and focusing on task-specific organization (Christensen \& Lægreid, 2006). Researchers (e.g. Pollitt et al., 2004, Christensen et al., 2007; Verhoest et al., 2010) suggest that in some countries public agencies have been created as instruments under logic of consequentiality (ends-means relationship); in other countries they have been adopted in response to the pressure of supranational institutions (Farazmand, 2002), while in some other countries they reflect historical tradition and culture (Randma \& Kickert, 2017). Different theories inform the phenomena of public sector reforms with special reference to the questions of why are agencies created, how they are designed, how they spread from one country to another, and the way they work in practice (Verhoest et al., 2010). Principal-agent theory is a widely recognized theoretical framework that underlies the NPM assumptions about how

4 World Development Report 1997: The State in a Changing World. New York: Oxford University Press 
structural features affect the autonomy/control of public agencies. Principal-agent theory especially focuses on the central problem of how the principal can monitor/ control the agent in the context of goal conflict and information asymmetry. Since the situations of goal conflict and information asymmetry are particularly prevalent in the public sector, the agency theory is an appropriate lens to study the control/ autonomy relationship between government and its agencies. Public mangers, who act as agents of the principal (ministers) to perform certain tasks, have some discretion in executing those tasks (Hood \& Dixon, 2015). In order to ensure that agents perform well, the principal put in place certain control mechanisms to channelize behavior in the desirable direction (Hood, 1991). Public management scholars have applied this theory to issues such as control, financial systems, automatizations, and performance contracts.

In understanding and designing public agencies, some scholars have used rational choice theory. Under the notion of instrumental rationality, formal structure of an organization has a major bearing on how organizations act and make decisions (Christensen et al., 2007). This theory lays more explicit emphasis on designing structure and analyzes public organizations on two dimensions for the purpose of division of work and coordination--differentiation and integration. Horizontal specialization is concerned with the division of functions on the same hierarchical level and is based on purpose, process, clientele, or geography. Vertical specialization, on the other hand, deals with allocation of the authority, tasks and functions across hierarchical levels. Similarly, the form of coordination may be either horizontal (coordination of tasks on the same level) or vertical (control mechanisms at different levels). The theory also suggests that autonomous agencies may be created for serving a particular purpose, client, or geography in order to sharpen focus, enhance efficiency, and achieve better control (Pollit et al., 2004).

Drawing on both agency theory and rational choice theory, we propose and test

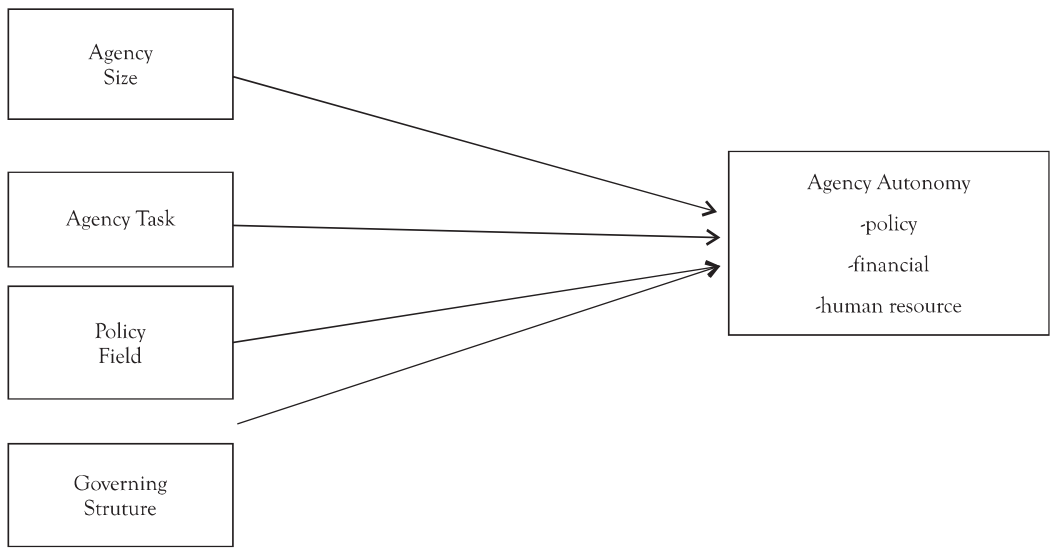

Figure 1: Structural Instrumental Model 
the following conceptual model, originally developed by Verhoest et al. (2010), as reflecting the agencification phenomenon in general and in KP (Pakistan) in particular:

This model shows that that many factors (policy field, agency size, task, and governing structure) exert contingent effect on the autonomy of an agency. One specific feature of an agency structure is its size in terms of staff and budget which determines its capacity (Christensen et al., 2007; Egeberg, 2003). A large size implies more resources at the disposal of agency to build its own expertise and power as well as pursue its own objectives (Diaz, 2017). Thus it can be hypothesized that:

$\mathrm{H}$ 1. Large agencies (staff size and/or budget) will have relatively more autonomy than small agencies.

A second factor which may determine autonomy of public agency is the nature of task which the agency performs. Under the logic of structural-instrumental perspective (Pollitt et al., 2004), the nature of the task influences the way autonomy is regarded by the agency as well as by the supervising authorities. Features of the task an agency is supposed to perform matter in different ways. Activities that produce observable outputs/outcomes that can be conveniently measures tend to be monitored more intensely by the supervising authorities than those which are difficult to observe and measure. Rational choice theorists believe that agencies engaged in general public services or business-type activities will have more autonomy than those involved in regulation, policy advice, and exercising other forms of public authority (Verschuere, 2007). Consequently, the hypothesis is:

H. 2: Agencies engaged in service delivery as their primary task will have less autonomy than those performing other tasks

According to Pollitt et al. (2004), one possible indicator of an agency's autonomy is the policy area which it serves. On the basis of COFOG (Classification of Functions of Government) developed by the United Nations, agencies can be grouped into three categories: (a) agencies in social policy and welfare area (b) agencies in the economic policy domain, and (c) agencies in other policy areas. Agencies of the first kind are more politically salient due to their direct effect on and interaction with citizens (Pollitt, 2005) than agencies in economic or other policy areas where they interact with specific professional groups. A significant number of agencies in the economic policy domain are subjected to competition where they need to have relatively higher autonomy. Thus the hypothesis could be:

H. 3: Agencies within the social and welfare policy areas will have less autonomy than those working in other policy areas. 
Some agencies may be governed through a governing board which may have representatives from government and other interest groups (employees association, civil society etc.). According to Egeberg, (2003) and Stafford \& Stapleton (2017), governing boards at the top of an agency organizational structure seem to balance and reconcile conflicting interests and concerns at the same time. This implies that the existence of a board can manipulate political signals on their way down the hierarchy, thus creating opportunity for an agency's autonomy (Egeberg, 1994). Christensen (2001) and Christensen and Lægreid (2006) also contend that the existence of a board in agencies increases their autonomy. Thus one can expect that:

H. 4: An agency with governing board will have more autonomy than those without it.

\section{Methodology}

This research is a cross-sectional study which puts a conceptual model to test in field setting. According to Brewer (2000), a study carried out in field setting tends to have greater external validity (generalizability) than laboratory experiment. However, field studies fall short in attributing the given effects strictly to the presumed causes due to the existence of confounding variables (Bryman, 2012). Data for this research was collected from senior executives (CEO, Managing Director, HR Director, Finance Manager etc.) of all 36 autonomous/semi-autonomous agencies operating in KP (see annexure 1.) province primarily through COBRA (Comparative Public Organization Data Base for Research and Analysis) questionnaire. The unit of analysis is organization and senior executives acted as representatives of their respective organizations. The data was helpful in describing, comparing, and explaining various aspects of public agencies including their environment, autonomy and control mechanisms, and performance orientation. This questionnaire has already been tested and used in many countries (e.g. Norway, Sweden, Belgium, Denmark, Tanzania, and Finland etc.) for studying different aspects of autonomous/semi-autonomous organizations (e.g. Laegreid, Roness, \& Verhoest, 2011). Since, the respondents of this study were top executives, the researcher preferred to personally administer most of the questionnaires. The reason for focusing on individual senior officials was that the perceived autonomy/control is believed to be more important for the performance of an organization than legal autonomy. This approach proved to be very effective in increasing the possibility of response rate as well as clarifying various concepts used in the questionnaire. It also helped in getting insight into the personal experiences of respondents about governance problems in Khyber Pukhtunkhwa.

The core concepts involved in this study included agency size, agency task, policy field, governance structure, and autonomy of the agency. Two indicators are used to measure the agency size: (a) staff size, and (b) budget. Staff size in terms of the number 
of full time employees on payroll during December 2015. Budget was measured in terms of total expenditure (excluding capital expenditure) for year 2014-15. Budget and staff size have been clustered into three categories each using the criteria developed by Verhoest at al., 2010: 1. budget size of Rs. 0-10 million (small agency), Rs. 10-50 million (Medium agency), and Rs. 50 million and above (Large agency), 2. Staff size: 0-10 regular employees (small agency), 50-150 employees (medium agency), and 150 or more employees (large agency). The concept of agency task captures information about what the public agency does in terms of primary tasks and secondary tasks. A list of eleven tasks, as given in the COBRA survey, has been used in this study. The policy field variable is used to identify the policy area in which the agency operates.

The policy fields included in the questionnaire have been taken from the United Nations Classification of Functions of Government (COFOG). For the purpose of convenience in empirical analysis, the policy areas were grouped into two categories: (a). Welfare and social policy, (b) Economic and other policy. A value of 0 was assigned to the first category and 1 to the other. The variable of governing board was measured on dichotomous scale with (0) for no governance board and (1) indicating the existence of a governing board. An agency's autonomy has two dimensions including policy autonomy and managerial autonomy. Policy autonomy is divided into three dimensions, i.e. choice of the target group, selection of tasks, and choice of instruments to implement policies. Each dimension is measured using 7-point scale with 1 indicating lowest degree of autonomy (government takes the decision without consulting the agency) and 7 showing highest degree of autonomy (the agency takes the decision without consulting the minister or not restricted by any rules). Managerial autonomy is divided into two dimensions, i.e. personnel management autonomy and financial autonomy. Personnel management autonomy is measured along 4-point scale with 1 indicating lowest level of autonomy (the agency has no role in deciding on strategic or operational personnel matters) and 4 showing highest degree of autonomy (the agency can decide on personnel matters for all staff). Financial autonomy is measured along 3-point scale with 1 indicating lowest autonomy (the agency has got no say in raising and spending money at will) and 3 showing highest autonomy (the agency has complete power to raise and use financial resources).

\section{Results}

Before examining correlation between structural features of public agencies in $\mathrm{KP}$ and their effect on autonomy, it seems pertinent to describe some key aspects of the agencies. To begin with, most of the public agencies are relatively small in size (measured in terms of budget and number of staff). Agencies with 100 or less regular employees constitute $45 \%$ followed by $35 \%$ of agencies with employees between 
100 and 500. In terms of budget, $55 \%$ of public agencies have budgets less than 100 million as compared to $5 \%$ with a budget more than 1000 million. The task an agency performs is assumed to affect its autonomy. In $\mathrm{KP}$, most autonomous bodies (60\%) have been created for monitoring and regulation whereas $40 \%$ are engaged in public service delivery. In terms of policy field, most agencies $(65 \%)$ have been created in welfare and social fields and the rest (35\%) operate in economic and other fields. Governing boards is one of the salient features of public agencies in KP. $65 \%$ of all public agencies in KP have governing boards and only $35 \%$ are run without a governing board.

One of the main questions that this study attempted to address was the extent to which public agencies in KP perceive themselves as autonomous in terms of policy formulation, HR issues, and financial affairs. Policy autonomy is the ability of an agency to set goals/targets independent of the parent ministry. In KP, 20\% agencies reported that they set goals independently while $80 \%$ said they set goals in collaboration with parent ministry. Regarding HR autonomy, there has been a general trend toward decentralization in KP over the last 20 years. Most agencies $(60 \%)$ in $\mathrm{KP}$ were reportedly involved in strategic HR issues (e.g. setting criteria for selection, evaluation, promotion, and dismissal etc.). Public agencies, however, did not enjoy much autonomy in financial affairs in KP. Almost all agencies (80\%) depended on government for financing their activities and they did not have much discretion in shifting budget from one head to another (only 15\% agencies could shift budgets), taking loans, setting tariffs, or making agreements.

In addition to descriptive analysis of various aspects of agencies in $\mathrm{KP}$, the next questions relate to how various independent variables-structural features in particular-correlate with the autonomy and performance of public agencies. Bivariate analysis was conducted by using Kendell's Tau correlation technique and Mann-Whitney U test.

Starting with agency size and autonomy, it was found that size of an agency has a significant positive effect on strategic personnel autonomy $(0.768, p=0.01)$ and operational personnel autonomy $(0.694, \mathrm{p}=0.01)$ but no statistically significant relationship with financial management autonomy $(0.413, p=0.05)$. It means that large agencies generally enjoy more autonomy with respect to personnel issues (e.g. determining levels of pay for employees, setting conditions for promotions, appointments and dismissals for both groups and individuals) than smaller agencies. This result confirms Hypothesis (H1). Agency size is also correlated positively with policy autonomy $(0.608, p=0.01)$ which means that large agencies can acquire more resources which translate into power and expertise, thus pursuing their own goals. The reason for weak correlation between agency size and financial autonomy may be due to the fact that most agencies in KP irrespective of their size depend primarily on government grants 
Table 1: Correlations-Size and Autonomy of Public Agencies

\begin{tabular}{|c|c|c|c|c|c|}
\hline & Size & SPA & OPA & FMA & PA \\
\hline Size & 1 & $.768^{* *}$ & $.694^{* *}$ & $.413^{*}$ & $.608^{* *}$ \\
\hline & & $(.000)$ & $(.000)$ & $(.013)$ & $(.000)$ \\
\hline SPA & - & 1 & $.615^{* *}$ & $.558^{* *}$ & $.725^{* *}$ \\
\hline & & & $(.000)$ & $(.001)$ & $(.000)$ \\
\hline OPA & - & - & 1 & $.439^{*}$ & $.500^{* *}$ \\
\hline & & & & $(.011)$ & $(.004)$ \\
\hline FMA & - & - & - & 1 & $.446^{* *}$ \\
\hline & & & & & $(.010)$ \\
\hline PA & - & - & - & - & 1 \\
\hline
\end{tabular}

${ }^{*}$ Correlation is significant at the 0.05 level (2-tailed)

** Correlation is significant at the 0.01 level (2-tailed)

which invite tight controls (e.g. internal and external audit) from the government to ensure financial discipline.

Looking at the relationship between agency task and various aspects of autonomy, it is evident from Table 2 that agencies performing regulatory activities enjoy more

Table 2: Differences in Autonomy Between Public Agencies Engaged in Regulation and Those Delivering Service (Mann-Whitney U Test)

\begin{tabular}{|c|c|c|c|c|}
\hline Task & SPA & OPA & FMA & PA \\
\hline Regulation (mean rank) & 30.75 & 35.00 & 26.00 & 30.81 \\
\hline Service Delivery (mean rank) & 15.15 & 10.00 & 18.00 & 15.29 \\
\hline Mann-Whitney U & 46.00 & 60.00 & 54.00 & 45.00 \\
\hline Sig. & .000 & .000 & .000 & .000 \\
\hline
\end{tabular}

autonomy, expressed in terms of strategic and operational personnel autonomy as well as financial and policy autonomy, than agencies engaged in direct service delivery. The hypothesis (H2), therefore, finds support from empirical evidence.

The policy field which an agency serves appears to have an impact on its autonomy. Table 3 shows that agencies operating in economic and other policy fields have relatively more autonomy in strategic personnel issues, financial management, and policy formulation than those serving in welfare and social domains. Agencies operating in welfare and social policy domains are generally politically salient and affect 
Table 3: Differences in Autonomy Between Public Agencies Engaged In Welfare and Social Activities and Those Working In Economic Or Other Fields (Mann-Whitney U Test)

\begin{tabular}{|c|c|c|c|c|}
\hline Policy Field & SPA & OPA & FMA & PA \\
\hline $\begin{array}{c}\text { Welfare and Social (mean } \\
\text { rank) }\end{array}$ & 11.85 & 17.23 & 20.50 & 12.92 \\
\hline $\begin{array}{c}\text { Economic and Other (mean } \\
\text { rank) }\end{array}$ & 33.71 & 29.86 & 24.04 & 32.57 \\
\hline Mann-Whitney U & 60.00 & 60.00 & 38.50 & 38.00 \\
\hline Sig. & .000 & .000 & .000 & .000 \\
\hline
\end{tabular}

relatively more citizens (Pollitt, 2005) which make them subject to greater controls. On the other hand, agencies in the economic policy area generally operate in competitive environment which certainly require more autonomy at strategic as well as operation level to perform well. Hypothesis $(\mathrm{H} 3)$ stands confirmed.

The existence of governing board or otherwise affects an agency's autonomy. The Table 4 below shows that agencies in KP differ in autonomy as a result of existence of governing board. Agencies with governing board have high strategic personnel autonomy and operational personnel autonomy with statistical significance of $10 \%$ as compared to those without a board thus supporting hypothesis (H4). The financial autonomy and policy autonomy of agencies with governing board are although higher than those without a board but the results are not statistically significant. The

Table 4: Differences in Autonomy Between Public Agencies With and Without A Governing Board

\begin{tabular}{|c|c|c|c|c|}
\hline Governing Board & SPA & OPA & FMA & PA \\
\hline Yes (mean rank) & 32.09 & 34.00 & 24.73 & 26.55 \\
\hline No (mean rank) & 13.01 & 11.44 & 21.00 & 18.00 \\
\hline Mann-Whitney U & 62.50 & 55.00 & 44.00 & 46.00 \\
\hline Sig. & .000 & .000 & .000 & .000 \\
\hline
\end{tabular}

results, in general are not statistically significant but the difference in autonomy may be regarded as meaningful given the fact that the results are based on data about the entire population rather than sample. Christensen (2001) and Egeberg (2003) have reported similar results with argument that a governing board blurs political signals coming down the hierarchy, thus giving greater autonomy to the agency. 


\section{Discussion and Conclusion}

Like other countries, Pakistan and especially Khyber Pukhtunkhwa (KP) province is making efforts to modernize its institutions to deal with formidable and complex challenges that it confronts. The most significant trend of public sector reforms in $\mathrm{KP}$ is toward changing the structure and functioning of the public sector by creating specialized agencies within large bureaucracy. Although the government of KP is adapting to modern reforms under the umbrella of NPM (New Public Management), there has been lack of scientific evidence about how structural features of a public agency might affect its autonomy in the context of KP. This study dealt with the question by describing and comparing various agencies created after 1980s.

To begin with, the results of this study shows that structural features of public agency do count in determining its autonomy. Two specific features of an agency structure are its size in terms of staff and budget which determine its capacity (Christensen et al., 2007; Egeberg, 2003). A large size implies more resources at the disposal of agency to build its own expertise and power as well as pursue its own objectives. In KP, agencies with large size (expressed in terms of budget and regular staff size) enjoy relatively more autonomy in personnel matters and policy issues than small agencies. Similarly, agencies with economic field as their policy domain have more autonomy than those in the welfare and social field. A significant number of agencies in the economic policy domain are subjected to competition where they need to have relatively higher autonomy (Pollitt, 2005). Moreover, agencies engaged in regulations were found to have more autonomy than those delivering service. A public agency, which is mandated to carry out activities which are complex in natures, will enjoy more autonomy than the ones which perform simple and observable activities. Generally speaking, regulatory activities are more embedded and complex than service activities and hence enjoy more autonomy (Verschuere, 2007). Public agencies with governing boards had relatively higher autonomy in personnel matters and financial issues than those without them. This implies that the existence of a board can manipulate political signals on their way down the hierarchy, thus creating opportunity for an agency's autonomy (Egeberg, 1994).

Both the existing literature and finding of this study suggest that many factors affect the nature, processes, and intentions behind creating public sector agencies. Differences in politico-administrative tradition, culture, legal systems, and stage of economic development are reflected in the way public sector organizations are created and managed. Moreover, the agency form as an organizational model is characterized by diversity and heterogeneity both in types of tasks and organizational features (Verhoest et al., 2010) which in turn has increased the need for more coordination. 
In line with the claims of NPM, agencies are a new phenomenon in KP. There have been a number of autonomous bodies with functions to implement policies, carry out public tasks, and regulate private sectors after the NPM fashion during and after 1980s. Although, some agency-like bodies (e.g. PHYDO, University of Peshawar, and Public Service Commission) have been there since 1947, created away from the core bureaucracy to free them from strict regulations about the use of resources in order to give them more flexibility to act efficiently and innovatively, but the momentum in agencification is a recent phenomenon. The interviews conducted for this revealed that an important rationale behind creating specialized agencies in KP was to build and/or integrate specialized expertise on a specific issue which is more often scattered across ministries (e.g. Peshawar Development Authority). However, many agencies (such as Public Safety Commission) owe their existence to no explicit rational considerations (economy, efficiency, flexibility) rather they are either created under pressure from international organizations and donors or simply because other countries/provinces have had such agencies (mimicry). A number of respondents agreed that agencification has occurred in KP with a view to open up room for blame-avoidance by politicians, increase patronage, and gain political control over specific parts of the public sector (e.g. PDMA, Public Safety Commission).

As there is no single motive/reason behind agencification, there is no single best agency model that can be applied across various sectors. The advocates of NPM would make us believe that agencies follow similar prototype (disaggregated organization which enables more business-like management) everywhere but as data collected for this study showed that agencies in KP offer considerable diversity in terms of level of autonomy, governing structure, and steering and control mechanisms. This assertion is in line with Pollitt et al. (2004) and Verhoest et al. (2010) who contend that agencies that are actually governed according to the NPM model are very rare and hard to find in practice. The NPM ideal type agency is translated and adapted by every country according to its peculiar political-administrative environment and $\mathrm{KP}$ is no exception in this regard. The data collected for this study reveal that there is no single reform model rather a phenomenon which reflects a complex combination of features from traditional administration (bureaucracy), new public management, and post-NPM, some of them even conflict one another.

\section{Policy Implications of the Study}

This study reveals that organizations in the public sector are constantly changing to adapt to environmental pressures or the change could be the result of culturally-oriented evolutionary processes leading to increased complexity. So reforming public organizations has become a rule rather than exception. An important finding of the 
study is that public agency as a distinct organization has become quite popular in KPK since 1980s but there is hardly any agreement among the policy makers and administrators about what an agency really is and which autonomy/control mechanisms make it more effective.

Another finding of the study is the empirical diversity in public agencies at KPK in sharp contrast to the standard global reform models (NPM in particular). Multiple factors (political, economic, and cultural) work together in a complex way (Christensen \& Laegreid, 2006) which require a unique reform model to reconcile and balance competing interests and values. In other words, policy makers have to look beyond a single model to reform public organizations, although NPM still dominates the overall scene of reforms.

\section{Limitation and Future Research Direction:}

The results, although based on data collected from almost all autonomous/ semi-autonomous public agencies operating in Khyber Pukhtunkhwa, are not generalizable across the board without considering some inherent limitations of the study especially related to the research design used. First, the data was collected from one political-administrative context which, though important for controlling contextual differences (Delery \& Doty, 1996), constrains external validity. Therefore, contextual differences need to be considered while making sense of the results of this study.

Another limitation of this study is that all data collected for this study regarding various aspects of autonomy and performance was perceptual in nature. A better option could have been objective data obtained from documents depicting actual autonomy and performance (such as minutes of meetings and annual performance reports) but this could not be done due inaccessibility to official records. However, it has been widely recognized that perception is more important than reality and is a better indicator of both autonomy and performance of an organization.

The findings of this study when viewed along with its limitations single out some key areas for further research in order to better understand the phenomenon of agencification. One important area to explore could be inter-provincial comparison of public agencies in terms of autonomy and performance. This would highlight the role context plays in determining the structural and cultural features of agencies with their impact on autonomy/mechanisms. A comparative study of provincial and federal agencies may also be undertaken to understand commonalities and differences in structure, culture, and autonomy of agencies.

Another area to investigate is to compare autonomous agencies with other mainstream public organizations in terms of performance. Such a study will reveal 
the effectiveness of agencification particularly with reference to whether agencies come into existence as a result of instrumental rationality, cultural appropriateness, or simply as a matter of international fashion.

\section{References}

Alonso, M., Clifton, J., \& Díaz-Fuentes, D. (2015). Did new public management matter? An empirical analysis of the outsourcing and decentralization effects on public sector size. Public Management Review, 17(5), 643-660.

Bertelli, M., Sinclair, J., \& Lee, H. (2015). Media Attention and the Demise of Agency Independence: Evidence from a Mass Administrative Reorganization in Britain. Public Administration, 93(4), 1168-83.

Brewer, D. (2000). Ethnography: Understanding social research. Oxford University Press

Bryman, A. (2012). Understanding social research. Oxford University Press

Chamon, M. (2016). EU agencies: Legal and political limits to the transformation of the EU administration. Oxford University Press, Oxford.

Christensen, G. (2001). Bureaucratic autonomy as a political asset. In B. G. Peters and J. Pierre (eds), Politicians, bureaucrats and administrative Reform. London, Routledge.

Christensen, T., Lægreid, P., Roness, G. \& Røvik, A. (2007). Organization theory and the public sector: Instrument, culture, myth. London, Routledge.

Christensen, T., \& Lægreid, P. (2006). Autonomy and regulation: Coping with agencies in the modern state. Edward Elgar Publishing.

Dan, S. (2014). The effects of agency reform in Europe: A review of the evidence. Public Policy and Administration, 29(3), 221-240.

Delery, J. E., \& Doty, D. H. (1996). Modes of theorizing in strategic human resource management: Tests of universalistic, contingency, and configurational performance predictions. Academy of Management Journal, 39(4), 802-835.

Diaz, G. (2017). The contractual and administrative regulation of public-private partnership. Utilities Policy, 48, 109-121.

Egeberg, M. (1994). Bridging the gap between theory and practice: The case of administrative policy, Governance, 7(1), 83-98

Egeberg, M. (2003). How Bureaucratic structure matters: an organizational perspective. In B. G. Peters and J. Pierre (eds), Handbook of public administration. London, Sage.

Farazmand, A. (2002). Administrative reforms in developing nations. London.

Held, D. (2004). Political Globalization, in D. Held, Global Covenant: The Socia Democratic Alternative 
to the Washington Consensus, Cambridge, Polity Press.

Held, D. (1984). Beyond Liberalism and Marxism?, in The Idea of the Modern State, eds G. McLennan, D. Held and Stuart Hall, Milton Keynes: Open University Press.

Hood, C. (1991). A public management for all seasons. Public Administration, 69(1),3-19.

Hood, C., \& Dixon, R. (2015). A government that worked better and cost less? Evaluating three decades of reform and change in UK central government. Oxford: Oxford University Press.

Hussain, I. (2005). Key issues in managing Pakistan's economy. Lahore Journal of Economics.10, Special issue, $1-26$.

James, O., \& Van Thiel., S. (2011). Structural devolution to agencies. In T. Christensen \& P. Laegreid (Eds.), Ashgate research companian to new public management (pp. 209-222). Aldershot: Ashgate Publishing.

Jonker, J. (2012). Countries compared on public performance: A study of public sector performance in 28 countries. The Hague: The Netherlands Institute for Social Research/SCP.

Kennedy, C. (1988). Bureaucracy in Pakistan. Oxford University Press.

Keynes, .M. (1936). The general theory of employment, interest and money. Harcourt,Brace and Company, New York, U.S.A.

Leagreid, P., \& Verhoest, K. (2010). Governance of public sector organizations: proliferation, autonomy, and performance. Hampshire: Palgrave Mcmillan.

Laegreid, P., Roness, P.G. \& Verhoest, K. (2011). Explaining the innovative culture and activities of state agencies, Organization Studies, 32(10), 1321-1347.

Meyer, W., \& Rowan, B. (1977). Institutionalized organizations: Formal structure as myth and ceremony. American Journal of Sociology, 83(2)340-63.

O'Connor, J. (1973). The fiscal crisis of the state. New York, St Martin's Press.

Overman, S., Van Thiel, S., \& Lafarge, F. (2014). Resisting governmental control: how semi-autonomous agencies use strategic resources to challenge state coordination. International Review of Administrative Sciences, 80(1), 1-10.

Pollitt, C. (1993). Managerialism and the public services, Oxford: Blackwell.

Pollitt, C., Talbot, C., Caulfield, J., \& Smullen, A. (2004). Agencies: how governments do things through semiautonomous organizations, Basingstoke, Palgrave/Macmillan.

Pollitt, C. (2005). Ministries and agencies: Steering, meddling, neglect and dependency. In M. Painter and J. Pierre (eds), Challenges to state policy capacity: global trends and comparative perspectives. Basingstoke, Palgrave Macmillan. 
Randma-Liiv, T., \& Kickert, W. (2017). The impact of the fiscal crisis on public administration reforms: comparison of 14 European countries. Journal of Comparative Policy Analysis: Research and Practice, 19(2), 155-172.

Rizwan, A., \& Jadoon, I. (2010). Agencification in Pakistan: A comparative study of service delivery and regulatory agencies. Paper presented in $32^{\text {nd }}$ International Conference, Touslouse, France.

Roness, P., Verhoest, K., Rubecksen, K., \& MacCarthaigh, M. (2008). Autonomy and regulation of state agencies: reinforcement, indifference or compensation? Public Organization Review, 8(2), 155-174.

Scott, C. (2016). Challenges for regulation in crisis. In M. Lodge (ed.) Regulation scholarship in crisis? CARR Discussion Paper No. 84.

Shafqat, S. (1997). Civil-military relations in Pakistan: From Zulfikar Ali Bhutto to Benazir Bhutto. Westview Press.

Stafford, A., \& Stapleton, P. (2017). Examining the use of corporate governance mechanisms in public-private partnerships: why do they not deliver public accountability? Australian Journal of Public Administration, 76(3), 378-391.

Stiglitz, E. (1998). The private uses of public interests: incentives and institutions, Journal of Economic Perspectives, 12(2), 3-22.

Sullen, A. (2010). The application of new public management doctrines in developing world: an exploratory study of the autonomy and control of executive agencies in Tanzania. Public Administration and Development, 30(5), 345-354.

Verhoest, K., Roness, G., Verschuere, B., Rubecksen, K., \& MacCarthaigh, M. (2010). Autonomy and control of state agencies. Comparing states and agencies, Basingstoke: Palgrave Macmillan.

Verschuere, B. (2007). The autonomy-control balance in flemish arm's length public agencies. Public Management Review, 9(1), 107-133 


\section{Annexture-1}

\begin{tabular}{|c|c|c|}
\hline Sr. No. & Agency & Respondent \\
\hline 1. & Provincial Disaster Management Authority & Regional Director \\
\hline 2. & Peshawar Development Authority & Director Planning \\
\hline 3. & University of Peshawar & Treasurer \\
\hline 4. & Sarhad Hydel Development Organization & Director Finance \\
\hline 5. & Khyber Teaching Hospital & MS \\
\hline 6. & Frontier Highway Authority & Director \\
\hline 7. & Frontier Education Foundation & MD \\
\hline 8. & Education Testing \& Evaluation Authority & Executive Director \\
\hline 9. & Bank of Khyber & MD \\
\hline 10. & Textbook Board Peshawar & Chairman \\
\hline 11. & Public Safety Commission & Chairman \\
\hline 12. & Sarhad Development Authority & Chairman \\
\hline 13. & Provincial Transport Authority & Secretary \\
\hline 14. & Environmental Protections Authority & DG \\
\hline 15. & Provincial Election Authority & Regional Director \\
\hline 16. & Higher Education Regulatory Authority & Secretary \\
\hline 17. & Health Regulatory Authority & $\mathrm{CEO}$ \\
\hline 18. & Public Service Commission & Chairman \\
\hline 19. & IMSciences & Director \\
\hline 20. & University of Malakand & Registrar \\
\hline 21. & Directorate of Commerce \& TE & DG \\
\hline 22. & Directorate of Sports & Director \\
\hline 23. & KP Revenue Authority & DG \\
\hline 24. & University of Haripur & $\mathrm{VC}$ \\
\hline 25. & $\mathrm{HMC}$ & Director Finance \\
\hline 26. & Provincial Housing Authority & Director \\
\hline 27. & LRH & Director Finance \\
\hline 28. & SBBU & Campus Director \\
\hline 29. & Directorate of Archaeology \& Museums & Director \\
\hline 30. & KP IT Board & $\mathrm{MD}$ \\
\hline 31. & Directorate of Stationery \& Printing & Director \\
\hline 32. & Directorate of Provincial Buildings & Director \\
\hline 33. & Directorate of Worker Welfare Board & Director \\
\hline 34. & Local Council Board & Chairman \\
\hline 35. & Directorate of Agriculture Training & Director \\
\hline 36. & Board of Investment & MD \\
\hline
\end{tabular}

